\title{
The effects of cold on a partially denervated muscle
}

\author{
P M H RACK, * J E FOX $\dagger$ \\ From the Department of Physiology, The Medical School, Birmingham* and the Midland Centre for \\ Neurosurgery and Neurology, $\uparrow$ Smethwick, West Midlands, UK
}

SUMMARY The abductor digiti minimi of a patient had undergone partial denervation with some subsequent re-innervation. Cooling of the muscle caused a severe reduction in the EMG and force which accompanied either voluntary effort or tetanic nerve stimulation, but it had little effect on the response to single stimuli. The ineffectual attempts at voluntary contraction of the cooled muscle did, however, block the response to single nerve stimuli. Administration of cholinesterase inhibitors did not improve neuromuscular transmission in the cooled muscle, but usually made it worse. It is concluded that depolarisation block may contribute to the weakness of cooled denervated muscles.

Patients with disorders of peripheral nerve conduction often complain of particular weakness during cold weather. It is well known that changes in the temperature of normal human muscles affect their performance $^{12}$ and there have been numerous investigations of the effects of temperature on other mammalian muscles. There is, however, little information about the effects of cooling on partially denervated or re-innervating muscles.

The present investigation was carried out on a subject in whom cooling of a limb exacerbated the effects of a pressure neuropathy. The investigation involved a degree of discomfort and we therefore report results from only a single case and a normal control subject (the two authors of this report). A brief report has already appeared. ${ }^{3}$

\section{Subject}

The subject was a man of 51 years who had injured his cervical spine 27 years earlier, fracturing two articular processes. In the 6 months before the present investigation he had developed weakness and wasting of the right wrist and finger extensor muscles, abductor digiti minimi and interossei, along with some sensory loss in the distal parts of the medial three fingers. There were similar, though milder neurological changes on the left side. Neck movements were restricted, and radiological examination showed degenerative changes in vertebrae C5-7.

Address for reprint requests: Professor P M H Rack, Department of Physiology, The Medical School, Birmingham B15 2TJ, UK.

Received 3 April 1986 and in revised form 21 July 1986. Accepted 26 July 1986
Routine electromyography of the abductor digiti minimi (ADM) revealed an excess of polyphasic potentials and a reduced interference pattern, but no evidence of active denervation. Motor conduction velocity was reduced to $39 \mathrm{~m} / \mathrm{s}$ around the elbow, but in the forearm and upper arm it was $54-56 \mathrm{~m} / \mathrm{s}$. The weakness involved muscles supplied by more than one peripheral nerve, and it was assumed to arise from root compression. However, at the time of this investigation the interossei and ADM were the most severely affected, and the slow ulnar nerve conduction around the elbow, suggested a "double-crush"4 of the motor fibres to these muscles, with compression in the cervical region and at the elbow.

\section{Methods}

The hand was placed supine in a plaster of paris mould, only the little finger being free to move. EMG activity was recorded from a subcutaneous needle electrode overlying the ADM with reference to a distant return lead; a transducer ${ }^{5}$ attached to the little finger measured the abducting force. The ulnar nerve was stimulated at the wrist through surface electrodes which were fixed firmly to the skin in the optimal position; $\mathbf{0} \cdot 2 \mathrm{~ms}$ stimulus pulses were used at amplitudes $150 \%$ of those needed for a maximum motor response. The combination of a securely attached electrode and the plaster of paris mould ensured stable stimulating conditions.

The limb was cooled by taking it out of the plaster mould and immersing it in iced water after wrapping it in a thin polythene bag. Immersion for 5 minutes was followed by hyperaemia of the skin, but re-immersion for a second time then led to more prolonged cooling. This was the usual procedure. EMG and force signals were recorded on magnetic tape and subsequently displayed on an oscilloscope for photography. A thermocouple fixed over the hypothenar eminence was sometimes used to monitor skin temperature. 


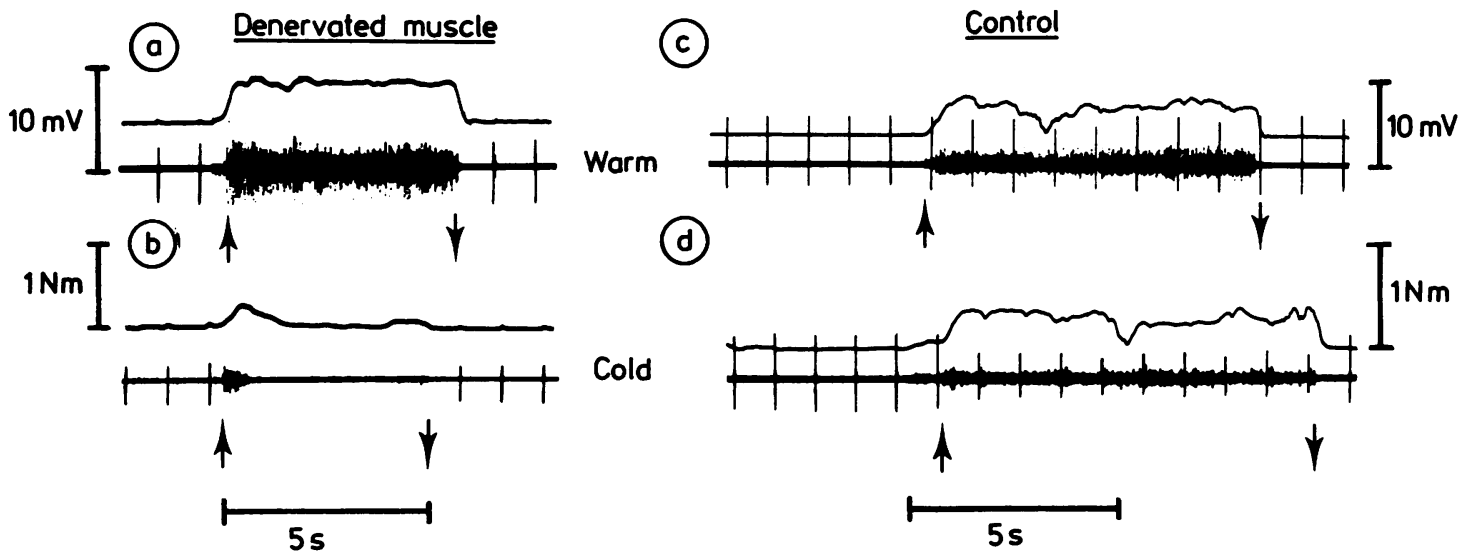

Fig 1 The effects of cooling: in each record, the ulnar nerve was stimulated once per second. The records begin and end with the subject relaxing, but he exerted a maximal voluntary abducting force during the time between the arrows. Lower records are EMGs recorded from over ADM; upper records show the abducting forces that accompanied a voluntary effort. (Twitch forces were not reliably recorded during stimulation, because antagonist muscles were also activated, and linkage to the force transducer became slack when the muscles were relaxed.) (a) and (b) are from the partially denervated muscle; (c) and (d) are normal controls. In (a) and (c) the limbs were normally warm; (b) and (d) were recorded after cooling.

\section{Results}

Voluntary contractions and single nerve stimuli

When the hand was normally warm, stimulation of the ulnar nerve led to clear compound action potentials in the ADM electromyogram; the subject could exert an almost normal voluntary abducting force $(0.5 \mathrm{Nm})$ at the metacarpo-phalangeal joint, and could sustain this force for $5 \mathrm{~s}$. The results can be seen in fig 1 (a) where nerve stimulation continued at 1 impulse/s, and the subject exerted a maximal force for 5 seconds.

After cooling the limb, ulnar nerve stimulation still led to clear compound action potentials, though their components were more dispersed, and their peak to peak amplitudes were smaller (first part of fig $1 \mathrm{~b}$ ). The subject could still exert a moderate voluntary force $(0.25 \mathrm{Nm})$, but this was very poorly sustained, and after about a second it collapsed to a level so low that it was barely detectable. The accompanying EMG activity was reduced in a similar way.

When during such a voluntary effort the ulnar nerve was externally stimulated (as it was in fig 1), it was notable that muscle action potentials were absent; this voluntary effort was thus preventing nerve impulses from reaching the muscle. This blockade still occurred in the cooled limb even though the voluntary effort then generated minimal electrical activity or contraction of the muscle fibres (fig lb). It thus appeared that the attempt at voluntary activity blocked some part of the neuromuscular transmission process at or before the neuromuscular junction.

Cooling of a normal hand caused the expected slowing of neuromuscular transmission, with dispersal of the different components of the compound EMG The electrical response to nerve stimulation was smaller during a voluntary effort, but it was not abolished, and the voluntary force was only slightly reduced (figs 1 (c) and (d)).

\section{Tetanic stimulation}

In search of a more objective and quantitative test, we examined the ADM electromyograms during tetanic nerve stimulation of the otherwise relaxed muscle. In the normally warm limb, tetanic stimulation of the ulnar nerve at $20-30 \mathrm{~Hz}$ gave compound muscle action potentials which were slightly larger in amplitude than with individual stimuli (fig 2, a); the normal control muscle gave a similar result. When, however, the partially denervated limb was cooled, the muscle action potentials during a tetanus became smaller than with separated stimuli (fig 2, b) and at the onset of a tetanus the first few EMG responses decreased successively in amplitude. Again it appeared that cooling had a particular effect on the neuromuscular transmission of rapidly repeating impulses.

In the lower part of fig 2 the individual muscle action potentials are displayed on a faster time base. Those records show that the different components of the muscle action potential were more dispersed in the cold muscle, and each of the components diminished in amplitude during tetanic stimulation. When higher 

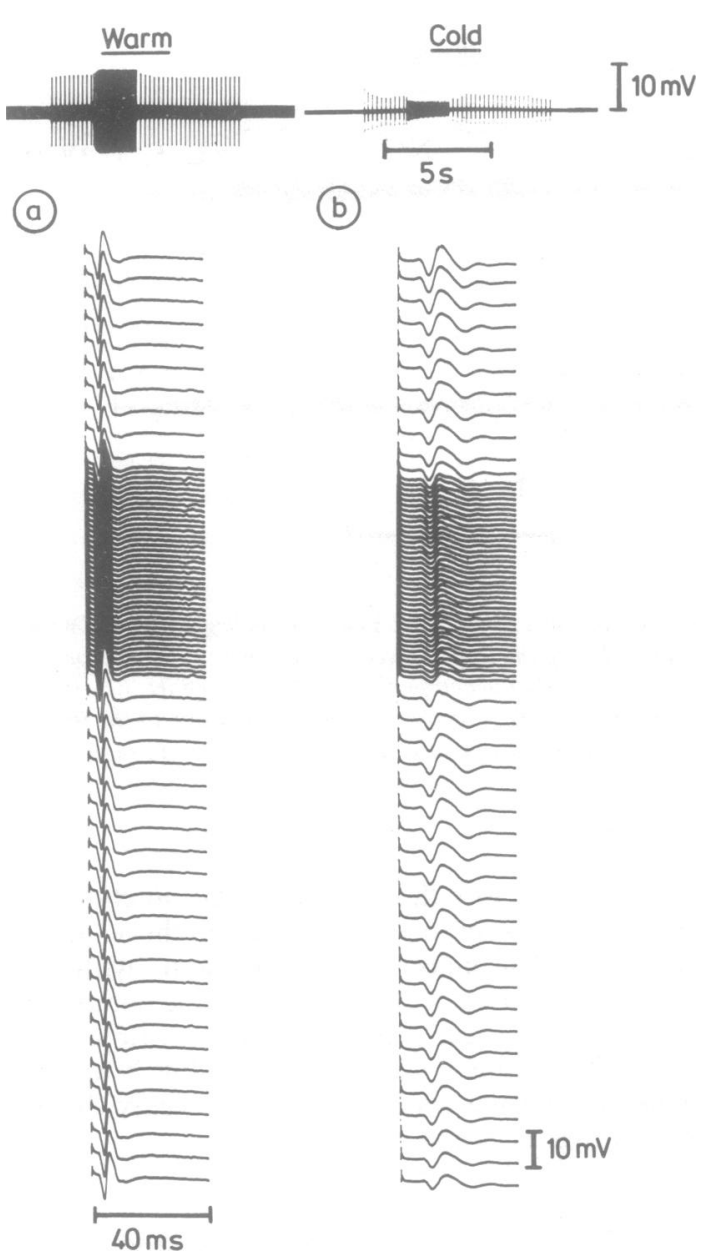

Fig 2 ADM EMGs recorded from the partially denervated limb during ulnar nerve stimulation. In each of the upper records the stimulus rate began at 5 impulses/s, and was then increased to 20/s before returning again to $5 / \mathrm{s}$. (a) Shows records obtained from the normally warm limb (skin temperature $\left.30^{\circ}\right)$; (b) shows records obtained after cooling (skin temperature $20^{\circ}$ ). To show more detail of the compound action potentials, the same sequences of record were re-photographed from triggered oscilloscope sweeps with a faster time base (lower records).

rates of stimulation were used this reduction in amplitude became still more striking, and the later components of the compound action potential often became variable and irregular (fig 3, b).

In our normal control subject, tetanic stimulation of the cooled limb was accompanied by only a small decrease in amplitude of the muscle action potentials (fig 4, $a$ and b).

\section{Choline esterase inhibitors}

The cold partially denervated limb responded to tetanic stimulation in a way that resembled the behaviour of myaesthenic muscles. ${ }^{6}$ It seemed possible, therefore, that cooling might have reduced the release of acetyl choline from the motor nerve terminals, ${ }^{78}$ as it also does in sympathetic ganglia. ${ }^{910}$ In order to test this hypothesis, we examined the effects of anticholinesterase drugs on the partially denervated limb after cooling (five trials), and when it was normally warm (three trials).

After intramuscular atropine, either edrophonium $(0.5-4 \mathrm{mg})$ or neostigmine $(1.9 \mathrm{mg})$ was injected intravenously. Neither drug prevented the reduction in amplitude of muscle action potentials during tetanic stimulation of the cooled limb, and all but the smallest doses actually aggravated this reduction beyond that which was seen with cooling alone. Figure 3 illustrates this result; in fig $3, \mathrm{~b}$ there was a reduction of muscle action potentials during tetanisation of the cooled limb; fig 3, c was recorded two minutes later, after intravenous administration of $1.9 \mathrm{mg}$ neostigmine. The neostigmine further reduced the response to the tetanic stimulation, and rendered the compound action potentials variable and irregular. It will be noted, however, that the muscle action potentials which followed the individual stimuli were actu-

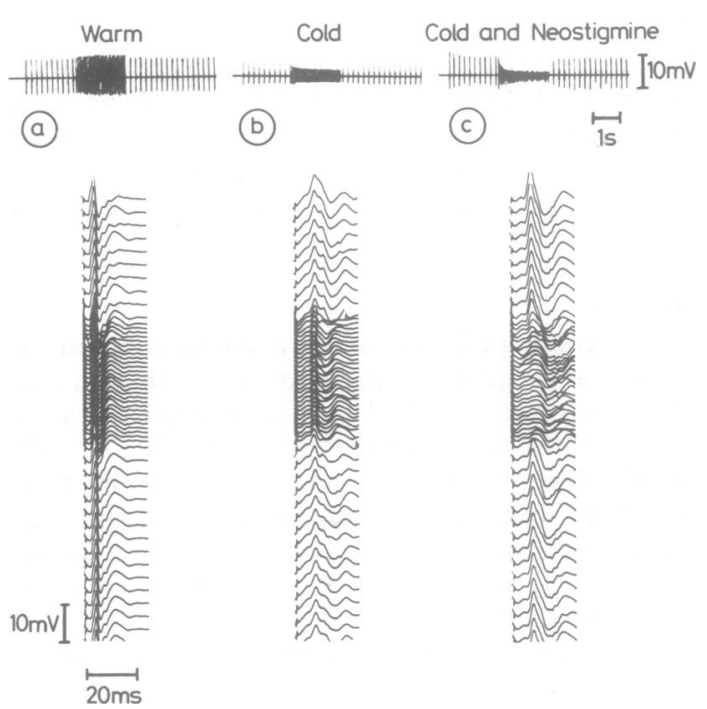

Fig $3 A D M E M G s$ recorded in the same way as for fig 2, but in each record the rate of stimulation was increased from $4 \cdot 5 / s$ to $27 / s$. (a) Was obtained from the warm muscle (skin temperature $31^{\circ} \mathrm{C}$ ); (b) after cooling, and (c) 2 min later after $1.9 \mathrm{mg}$ iv neostigmine (skin temperature was then $\left.21^{\circ} \mathrm{C}\right)$. At the higher frequency $(27 / \mathrm{s})$ the triggered sweeps in the lower part of the figure show the responses to only alternate stimuli. 

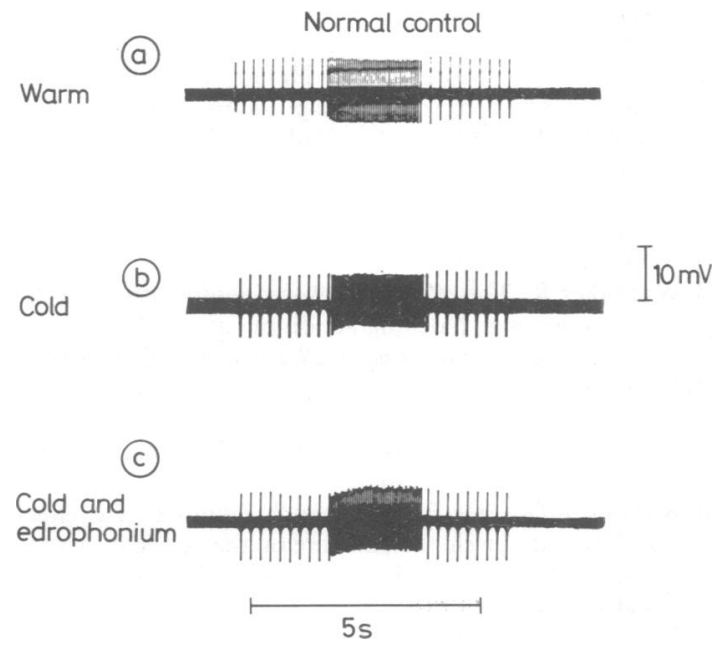

Fig 4 ADM EMGs recorded from a normal subject during ulnar nerve stimulation at 5 impluses/s and 20 impulses/s (as in fig 2). (a) The normally warm limb; (b) after cooling; (c) after cooling and $4 \mathrm{mg}$ iv edrophonium.

ally enhanced. Similar (though smaller) effects were seen with 2 or $4 \mathrm{mg}$ of edrophonium, and during stimulation at $20 \mathrm{impulses} / \mathrm{s}$, but $1 \mathrm{mg}$ of edrophonium merely enhanced the muscle response to individual stimuli, and $0.5 \mathrm{mg}$ had no detectable effect.

When the partially denervated muscle was normally warm, $4 \mathrm{mg}$ of edrophonium had no detectable effect on the responses to ulnar nerve stimulation. It was also without effect on a cooled normal muscle (see fig 4, c).

In assessing the response to anti-cholinesterase drugs, we always compared the effect of the drug with a preceding record; some re-warming could have occurred between these records, and it is likely that the true effect was larger than such records (fig 3) show.

\section{Discussion}

The results confirmed a subjective impression that during recovery from a partial denervation, a muscle was incapable of sustained contraction when it was cold. Furthermore, cooling appeared to have its major effect on transmission through the motor nerve terminals or the neuromuscular junction.

The contrast between a near-normal transmission of single impulses, and the severe blockade of impulse trains, gave the results a superficial resemblance to those seen in myasthenia gravis where repetition at rates as low as 3 impulses/s may be accompanied by decrement of the compound action potential. How- ever, their responses to anti-cholinesterase drugs were quite different: whereas the responses of myasthenic muscles to tetani are improved by these drugs, in the cold partially denervated muscle choline esterase inhibitors increased the EMG response to a single stimulus, but impaired the transmission of impulse trains, even though the dose of cholinesterase inhibitor was too small to have detectable effects on the warm muscle, or on other parts of the body.

This result suggests that part of the effect of cold may be associated with a depolarisation block such as occurs in normal subjects with large doses of cholinesterase inhibitors or with some of the more stable choline esters. ${ }^{1112} \mathrm{~A}$ number of other findings give some support to this suggestion:

(1) Denervated muscle fibres show a hypersensitivity to acetylcholine,$^{13}$ which is due to an extension of the sensitive area of the muscle fibre membrane; ${ }^{14}$ this additional sensitivity may persist for some time after re-innervation. ${ }^{15}$

(2) In re-innervating muscles the decline in tension during the course of a tetanus is aggravated by neostigmine and has therefore been attributed to the paralysing effect of an excess of acetylcholine. ${ }^{16}$

(3) The quantal content of endplate potentials is known to increase as temperature is reduced from $38^{\circ}$ to $20^{\circ} .{ }^{17}$

(4) Cooling is known to potentiate and prolong a depolarisation block in excised muscles, ${ }^{1819}$ in experimental animals, ${ }^{20}$ and in man. ${ }^{21}$

(5) In a human subject whose acetyl choline release was assumed to be diminished (the Eaton-Lambert syndrome), muscle responses to tetanic stimulation were enhanced by cooling, ${ }^{22}$ and similar changes are reported in myasthenia gravis. ${ }^{23}$

We conclude that a depolarisation block may contribute to the weakness of re-innervating muscles when they are cold.

\section{References}

1 Clarke RSJ, Hellon RF, Lind AR. The duration of sustained contractions of the human forearm at different temperatures. J Physiol (Lond) 1958;143:454-73.

2 Coppin EG, Livingstone SD, Kuehn LA. Effects on handgrip strength due to arm immersion in a $10^{\circ} \mathrm{C}$ water bath. Aviat Space Environ Med 1978;49:1322-6.

3 Fox JE, Rack PMH. The effect of cold on a partially denervated muscle. J Physiol (Lond) 1982;332:35P.

4 Lishman WA, Russell WR. The brachial neuropathies. Lancet 1961;2:941-7.

5 Joyce GC, Rack PMH. The effects of load and force on tremor at the normal human elbow joint. $J$ Physiol (Lond) 1974;240:375-96.

6 Desmedt JE. The neuromuscular disease of myasthenia gravis. 1 Electrical and mechanical responses to nerve 
stimulation in hand muscles. In: Desmedt JE, ed. New developments in electromyography and clinical neurophysiology. Prog Clin Neurophysiol vol 1. Basel: Karger, 1973:241-303.

7 Fatt P, Katz B. Spontaneous subthreshold activity at motor nerve endings. $J$ Physiol (Lond) 1952; 117:109-38.

8 Foldes EF, Kuze S, Vizi ES, Deery A. The influence of temperature on neuromuscular performance. $J$ Neurol Trans 1978;43:27-45.

9 Brown GL. The effects of temperature on the release of acetylcholine from sympathetic ganglia. J Physiol (Lond) 1954;124:26P.

10 Kostial K, Vouk VB. The influence of temperature on the acetylcholine output from a sympathetic ganglion. $J$ Physiol (Lond) 1956;132:239-41.

11 Burns BD, Paton WDM. Depolarisation of the motor end-plate by decamethonium and acetycholine. $J$ Physiol (Lond) 1951;115:41-73.

12 Zaimis EJ. Transmission and block at the motor endplate and in autonomic ganglia. Pharmacol Rev 1954;6:53-57.

13 Brown GL. The action of acetylcholine on denervated mammalian and frog's muscle. $J$ Physiol (Lond) 1937;89:438-61.

14 Miledi R. The acetylcholine sensitivity of frog muscle fibres after complete or partial denervation. J Physiol (Lond) 1960;151:1-23.

15 Miledi R. Properties of regenerating neuromuscular synapses in the frog. J Physiol (Lond) 1960;154: 190-295

16 Thomson JD, Morgan JA, Hines HM. Physiologic characteristics of regenerating mammalian nerve and muscle. Am J Physiol 1950;161:142-50.

17 Hubbard JI, Jones SF, Landau EM. The effect of temperature change upon transmitter release, facilitation and post-tetanic potentiation $J$ Physiol (Lond) 1971;216:591-609.

18 Whittaker R. The effect of lowered temperature on the neuromuscular blocking action of suxamethonium on the rat diaphragm $J$ Pharm Pharmacol 1962;14:803-7.

19 Harris JB, Leach GDH. The effect of temperature on end-plate depolarisation of the rat diaphragm produced by suxamethonium and acetylcholine. J Pharm Pharmacol 1968;20:194-8.

20 Bigland B, Goetzee B, Maclagan J, Zaimis E. The effect of lowered muscle temperature on the action of neuromuscular blocking drugs. J Physiol (Lond) 1958; 141:425-43.

21 Cannard TH, Zaimis E. The effect of lowered muscle temperature on the action of neuromuscular blocking drugs in man. $J$ Physiol (Lond) 1959;149:112-9.

22 Ward CD, Murray NMF. Effect of temperature on neuromuscular transmission in the Eaton-Lambert syndrome. J Neurol Neurosurg Psychiatry 1979;42:247-9.

23 Borenstein S, Desmedt MD. Local cooling in myasthenia. Arch Neurol 1975;32:152-7. 